\title{
Application of Artificial Neural Networks to Predict Inhibition in Probiotic Experiments
}

\author{
Ecren Uzun Yaylacl \\ Karadeniz Technical University, Faculty of Marine Sciences, 61530, Trabzon, Turkey \\ E-mail address: ecrenuzun@ktu.edu.tr \\ ORCID numbers of authors: \\ 0000-0002-2558-2487
}

Received date: 05.11 .2021

Accepted date: 06.12.2021

\begin{abstract}
Artificial neural networks (ANNs) provide a modeling approach that can be used in the in vitro stages of probiotic studies. The aim of the study was to evaluate the ability of multilayer perceptron (MLP) and radial-basis function (RBF) ANNs to predict the inhibition level of indicator bacteria in co-culture experiments performed at various initial concentrations. In both types of networks, time, initial concentrations of L. lactis and Aeromonas spp. were the input variables and the inhibition concentration of Aeromonas spp. was the output value. In the construction of the models, different numbers of neurons in the hidden layer, and different activation functions were examined. The performance of the developed MLP and RBF models was tested with root mean square error (RMSE), coefficient of determination $\left(\mathrm{R}^{2}\right)$ and relative error (e) statistical analysis. Both ANN models were showed a strong agreement between the predicted and experimental values. However, the developed MLP models showed higher accuracy and efficiency than the RBF models. The results indicated that ANNs developed in this study can successfully predict the inhibition concentration of Aeromonas spp. co-cultured with L. lactis in vitro and can be used to determine bacterial concentrations in the design of further experiments.
\end{abstract}

Keywords: Artificial Neural Network, In Vitro, Probiotic

\section{Introduction}

Aeromonas spp. are Gram-negative opportunistic bacteria with global distribution in various aquatic environments [1-2]. They are divided into two groups as motile and non-motile. The only non-motile Aeromonas species is A. salmonicida and is one of the important fish pathogens. Motile Aeromonas species (MAS) especially A. hydrophila, A. veronii and A. sobria may infect humans and lower vertebrates, including amphibians, reptiles, and fish [3-4]. MAS are considered as agents of motile aeromonad infections in aquatic animals [5]. MAS infections are characterised with exophthalmia, haemorrhages, ulcerations, skin lesions, acidic fluid, liver and kidney lesions in fish [6]. Motile Aeromonas species, especially A. hydrophila, cause great economic losses as it initiates outbreaks that cause massive fish mortality worldwide [3]. Antibiotics have been widely used for many years to prevent and control bacterial diseases in aquaculture [7]. The continuous applications of antibiotics cause accumulation of antibiotics in organs, disruption of the normal microbiota of the gut [8], and the development of antibioticresistant bacteria [9]. In the last decade, intensive use of antibiotic-based therapies against Aeromonas spp. has led to increased resistance of these bacteria to antibiotics such as oxytetracycline, tetracycline, and trimethoprim/sulfamethoxazole [10]. Therefore, 
environmentally friendly biocontrol agents such as probiotics can be used as an alternative approach to reduce these risk factors [11-12].

The use of probiotics is considered as an alternative method to prevent bacterial infections in aquaculture [13-14]. Lactic acid bacteria (LAB) are widely preferred in aquaculture as they are effective in disease control, improve intestinal microbial balance [15] and promote growth by increasing immune response [16]. LAB are "generally recognized as safe" (GRAS) microorganisms [17] and they are permanent inhabitants of the fish intestinal flora [18]. LAB produce various antimicrobial compounds such as organic acid, ethanol, hydrogen peroxide, diacetyl, carbon dioxide and bacteriocin that inhibit the growth of pathogenic bacteria [19-21]. The use of bacteriocins against Aeromonas spp. is an alternative method of inhibiting their growth [22]. Bacteriocins such as bacteriocin ST151BR, bacteriocin HKT-9 and plantarisin 35d secreted by LAB are effective against Aeromonas spp. has been previously reported in several papers [23-24].

There are many well-defined and commercially used probiotic strains worldwide, but the discovery of new strains still arouses the interest of scientists [25]. Many in vitro and in vivo methods are used in probiotic experiments. In vivo testing is expensive, time-consuming, and requires ethical committee approval. Therefore, reliable in vitro methods are required for the selection of potential probiotic strains [26]. In vitro tests are quite different from in vivo conditions, but they provide rapid and efficient screening for the search for new potential LAB strains [27-28]. Determination of bacterial growth or inactivation kinetics under ideal laboratory conditions are the methods applied in probiotic studies. Besides that, the mathematical modelling is preferred as a suitable tool for selecting beneficial strains, designing laboratory equipments, and determining growth parameters [29]. Predictive microbiology focuses on mathematical models that describe the effect of factors such as temperature, $\mathrm{pH}$, concentration, and inactivation kinetics of microbial growth [30]. In statistical models, it is difficult to express relationships between categorical data such as bacterial names, bacterial behavior and environmental parameters. Because categorical data are qualitative values and arithmetic operations cannot be performed [31]. Therefore, an alternative approach is required that can process large noisy datasets, learn relationships directly from the result of experiments, and predict without prior knowledge. In recent years, artificial neural networks (ANNs), which can describe nonlinear and complex relationships between data without any assumptions, have become an alternative to traditional regression models [32-33]. These are used to predict the outcome of any problem or situation in different disciplines by using some input values and relations [34]. ANNs imitate the functioning of the human brain. They can learn, recognize, and overcome complex problems in engineering and science [35]. A general ANN system consists of layers. The input layer receives signals from the external environment. There is no transaction in this layer. The hidden layer processes the information from the input layer. It can contain more than one layer. The output layer takes the weighted sum of the outputs of all hidden layer neurons and produces the output of the model [36].

The aim of this work was to examine the ability of ANNs to predict the inhibition concentration of Aeromonas spp. co-cultured with Lactococcus lactis. Two computational models based on the ANN approach are presented for the prediction. These models are, multilayer perceptron (MLP) and radial basis function (RBF). The data set was obtained from co-culture experiments performed in a controlled laboratory condition. The accuracy and validity of the developed MLP and RBF models were compared with the actual experimental results.

\section{Materials and Methods}




\subsection{Microorganisms and experimental design}

Microorganisms used in this study included Lactococcus lactis (MG754705.1), Aeromonas veronii (MG322191.1), Aeromonas sobria (ATCC 43979) and Aeromonas hydrophila (ATCC 7966). L. lactis and A. veronii were isolated from fish (Dicentrarchus labrax) and confirmed by sequencing of their 16S rRNA gene [37]. L. lactis was selected for its probiotic properties and Aeromonas species were used as indicator strains. Live L. lactis cells were selected because the inhibitory effect was better than the supernatants (unpublished data).

Experiments were carried out at different initial concentrations. These are $1.0 \times 10^{4} \mathrm{cfu} / \mathrm{mL}$, $1.0 \times 10^{6} \mathrm{cfu} / \mathrm{mL}$ and $1.0 \times 10^{8} \mathrm{cfu} / \mathrm{mL}$ for indicator bacteria and $1.0 \times 10^{4} \mathrm{cfu} / \mathrm{mL}, 1.0 \times 10^{5}$ $\mathrm{cfu} / \mathrm{mL}, 1.0 \times 10^{6} \mathrm{cfu} / \mathrm{mL}, 1.0 \times 10^{7} \mathrm{cfu} / \mathrm{mL}$ and $1.0 \times 10^{8} \mathrm{cfu} / \mathrm{mL}$ for L. lactis. L. lactis was co-cultured with each of the indicator bacteria separately at the indicated initial concentrations in tryptic soy broth (TSB) at $30^{\circ} \mathrm{C}, \mathrm{pH} 7.2$ for $120 \mathrm{~h}\left(150 \mathrm{rpm}^{-1}\right.$ in a shaker). Uncultivated TSB was used as a negative control. Samples $(100 \mu 1)$ withdrawn 0, 6, 24, 30, 48, 54, 72, 78, 96, 102 and $120 \mathrm{~h}$ from the fermented cultures and colonies were counted using the standard agar plate method. deMan Rogosa Sharpe (MRS) agar plates were used to select Lactococcus, while thiosulfate citrate bile salts sucrose agar (TCBS) plates were used for Aeromonas. The number of bacteria from plate counts were calculated as log values, which is a transformation of the microbiological data stabilizing the variance [38-39].

\subsection{Data sets used for modeling}

The input values in the networks represent the initial concentrations of L. lactis, Aeromonas spp. and the sampling times during fermentation. The estimated value of the developed networks is the concentration of Aeromonas spp. (cfu/mL) at the selected sampling points. The database consisted of 495 experimental data. These experimental data were divided into two groups as training and validation data sets. The models were built with training data (270 data, 3 indicator strains $\times 90$ sampling points per strain) which are different combinations of the values in Table 1 . The remaining data ( 225 data, 3 indicator strains $\times 75$ sampling points per strain) obtained at $6,30,54,78$, and $102 \mathrm{~h}$ was not added to the training data set, it was used for the model validation. These sampling points were selected to cover the entire co-culture process [39].

Table 1. Test parameters

\begin{tabular}{ccc}
\hline Time $(\mathrm{h})$ & L. lactis $(\mathrm{cfu} / \mathrm{mL})^{*}$ & Aeromonas spp. $(\mathrm{cfu} / \mathrm{mL})^{*}$ \\
\hline 0 & $1.0 \times 10^{8}$ & $1.0 \times 10^{8}$ \\
24 & $1.0 \times 10^{7}$ & $1.0 \times 10^{6}$ \\
48 & $1.0 \times 10^{6}$ & \\
72 & $1.0 \times 10^{5}$ & \\
96 & $1.0 \times 10^{4}$ & \\
120 & & \\
\hline
\end{tabular}

* initial concentrations

\subsection{Development of MLP and RBF models}

Multilayer perceptron and radial basis function are the most preferred algorithms of neural networks and are used to solve many problems. These algorithms belong to a general class of neural networks called feed-forward neural networks. In this network type, the information processing follows one direction from input neurons to output neurons [40]. In MLP and RBF, each neuron is independent in its layer but is connected to all neurons in the next layer with 
certain weights [41]. While there is no transaction in the input layer, the hidden layer and output layers process the data using the activation function. There are some differences between MLP and RBF neural networks [42]. The first and the most important difference between MLP and RBF networks is that they generate different learning strategies against problems [39]. RBFs generate local solutions and network outputs are obtained by specified hidden neurons in certain local accessible areas, while MLPs act globally, and network outputs are decided by all neurons $[42,43]$. In MLP networks, input signal activates many neurons, and these activated neurons participate in the calculation of the network output. In RBF networks, input signal activates a single neuron of the hidden layer and the weight between the activated hidden and output neurons participates in the calculation of the network output [44]. Second, MLP networks are structured one or several hidden layers, while RBF networks always have single hidden layer. Third, in MLP networks, neurons of the hidden layer usually contain a sigmoidal activation function (i.e., a logistic or hyperbolic tangent function), while in RBF networks, a radial-based activation function (usually a gaussian function).

The input and output values of each pattern were normalized in the range of $0.1-0.9$. The number of neurons in the hidden layer ranged from 2-20 for MLP networks and 2-30 for RBF networks. Weights are initialized into random values between 0.0001 and 0.001 . The appropriateness values of the error functions (sum of squares and entropy) were tested. After the network type is determined, the activation functions that transfer the signals from the previous layer to the next layer using a mathematical function are selected. In MLP networks, identity, logistic sigmoid, hyperbolic tangent, exponential, softmax, and gaussian activation functions were examined, and in RBP networks gaussian was tested. The architecture of MLP and RBF neural networks are illustrated in Fig 1. In this study, BFGS (Broyden-FletcherGoldfarb-Shanno) for MLP networks and RBFT (Reputation-based Byzantine Fault Tolerance) training algorithms for RBF networks were examined. 5000 networks were developed for MLP structures and 10000 networks for RBF-based structures. An artificial neural network model was performed in Statistica software 12 using the neural network module. The program code was written in $\mathrm{C}++$ language.

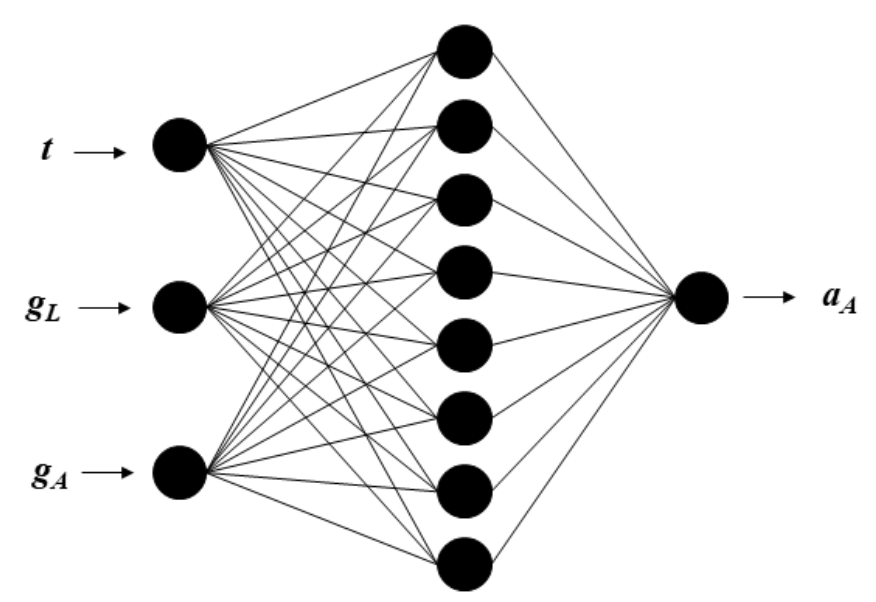

Fig. 1. The architecture of MLP and RBF neural networks

\subsection{Model performance}

In the study, the performance and accuracy of proposed MLP and RBF neural network models were tested with statistical parameters. The coefficient of determination $\left(\mathrm{R}^{2}\right)$, root mean square 
error (RMSE) and relative error (e) were used to conclude about the accuracy of both neural network models. These parameters calculated as follows:

$$
\begin{aligned}
R M S E & =\sqrt{\frac{1}{n} \sum_{i}^{n}\left(R_{\exp _{i}}-R_{A N N_{i}}\right)^{2}, \quad(i=1,2,3, \ldots, n)} \\
R^{2} & =1-\frac{\sum_{i}^{n}\left(R_{\exp _{i}}-R_{A N N_{i}}\right)^{2}}{\sum_{i}^{n}\left(R_{\exp _{i}}-\bar{R}_{\exp }\right)^{2}}, \quad(i=1,2,3, \ldots, n) \\
e & =\mid \frac{R_{\exp _{i}}-R_{A N N_{i}}}{R_{\exp _{i}} \mid \mathrm{x} 100, \quad(i=1,2,3, \ldots, n)}
\end{aligned}
$$

Where $R_{\text {expi }}$ and $E_{A N N i}$ are the experimental and calculated (with MLP and RBF) concentrations of the A. veronii, A. hydrophila and A. sobria. $n$ denotes the total number of sampling points and $\bar{R}_{\text {exp }}$ refers to average experimental value.

\section{Result and Discussion}

Co-culture experiments are the preferred method for evaluating the inhibition activity of $L$. lactis [45]. In this study, co-culture experiments of L. lactis with A. veronii, A. hydrophila and $A$. sobria were performed. The highest inhibition rate was detected after $120 \mathrm{~h}$ of incubation with Aeromonas spp. with an initial level of $1.0 \times 10^{4} \mathrm{cfu} / \mathrm{mL}$ and L. lactis with an initial level of $1.0 \times 10^{8} \mathrm{cfu} / \mathrm{mL}$. The inhibition rates were determined $54.4 \%$ for $A$. veronii, $48.3 \%$ for $A$. hydrophila and $38.8 \%$ for $A$. sobria. In agreement with previous studies, co-culture experiments showed that the inhibitory activity of L. lactis increased when the concentration of probiotic bacteria and the incubation time increased [46].

Gathering sufficient and valid data is one of the most important steps in the mathematical model development process [40]. In this study, a total of 495 experimental data obtained from in vitro co-culture assays of $A$. veronii, A. sobria, A. hydrophila with L.lactis were used in order to develop MLP and RBF models. 270 of these data were used to build the model while 225 of them were used to validation. Each set of data includes sampling points during co-culture assay and amounts of L. lactis and Aeromonas spp.

In this study, the comparison of the empirical correlations of the proposed models was evaluated by considering the root mean square error (RMSE), coefficient of determination $\left(\mathrm{R}^{2}\right)$ and relative error (e) statistical parameters. A lower RMSE value exhibits better efficiency [40]. The fact that the RMSE value is close to zero indicates that the predictive ability of the model has increased [47]. Although the RMSE values of the two networks are close to each other, the RMSE values of MLP are lower than RBF models. $\mathrm{R}^{2}$ is a statistical definition that reveals the numerical relationship between the data obtained from the experiment results and the network model predictions [43]. This value is defined as the square of the correlation coefficient and ranges from 0 to 1 . $\mathrm{R}^{2}>0.80$ means that there is a strong correlation between experimental values and model predictions [48]. $\mathrm{R}^{2}$ values of MLP were slightly higher than RBF models. A relative error is a type of error that shows how close the obtained values are to the real values. It was determined that MLP models had lower relative error rates than RBF models. Figures 2, 
4 and 6 indicate that both models exhibited high correlation coefficients. The high accuracy of the proposed models shows that these models have been successfully trained [40]. Although there are small differences between the RMSE, $\mathrm{R}^{2}$ and relative error values of both methods, it is seen that the MLP model has a better estimation capacity than the RBF model.

Figures 3, 5 and 7 show a comparison of the experimental results with the predictions of the MLP and RBF models as a function of time. It was determined that there is a high match between MLP models and experimental results. In the RBF models, it was determined that the predictions converged less with the data of the experimental results.

The RMSE of $A$. veronii was calculated as $\mathrm{RMSE}_{\mathrm{MLP}}=0.072111$ and $\mathrm{RMSE}_{\mathrm{RBF}}=0.084063$. The $\mathrm{R}^{2}$ of $A$. veronii was calculated as $\mathrm{R}_{\mathrm{MLP}}^{2}=0.998224$ and $\mathrm{R}_{\mathrm{RBF}}^{2}=0.997195$ (Fig. 2).

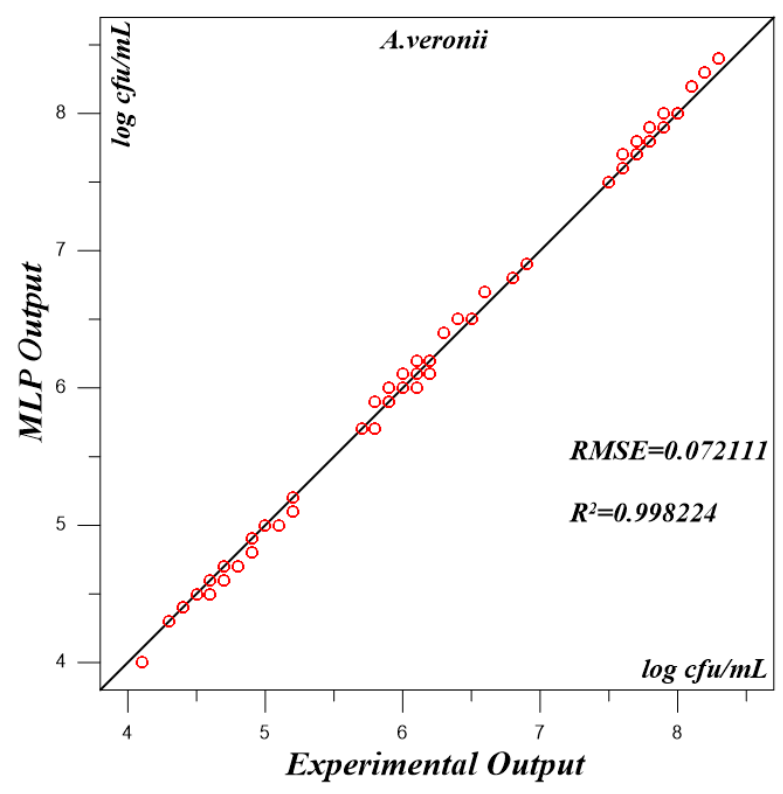

(a)

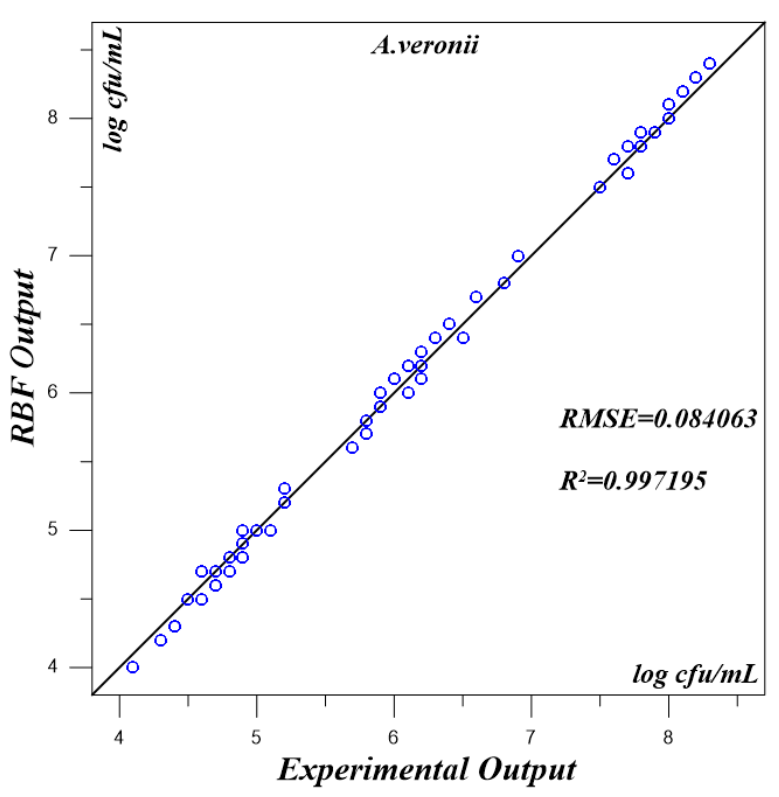

(b)

Fig. 2. Correlation between neural network model predictions and experimental outputs for A. veronii

Figure 3 shows the amount of $A$. veronii co-cultured with L. lactis. As shown in the figure, the average relative errors of $A$. veronii were calculated as $e_{M L P}=0.85 \%$ and $e_{R B F}=1.19 \%$. 

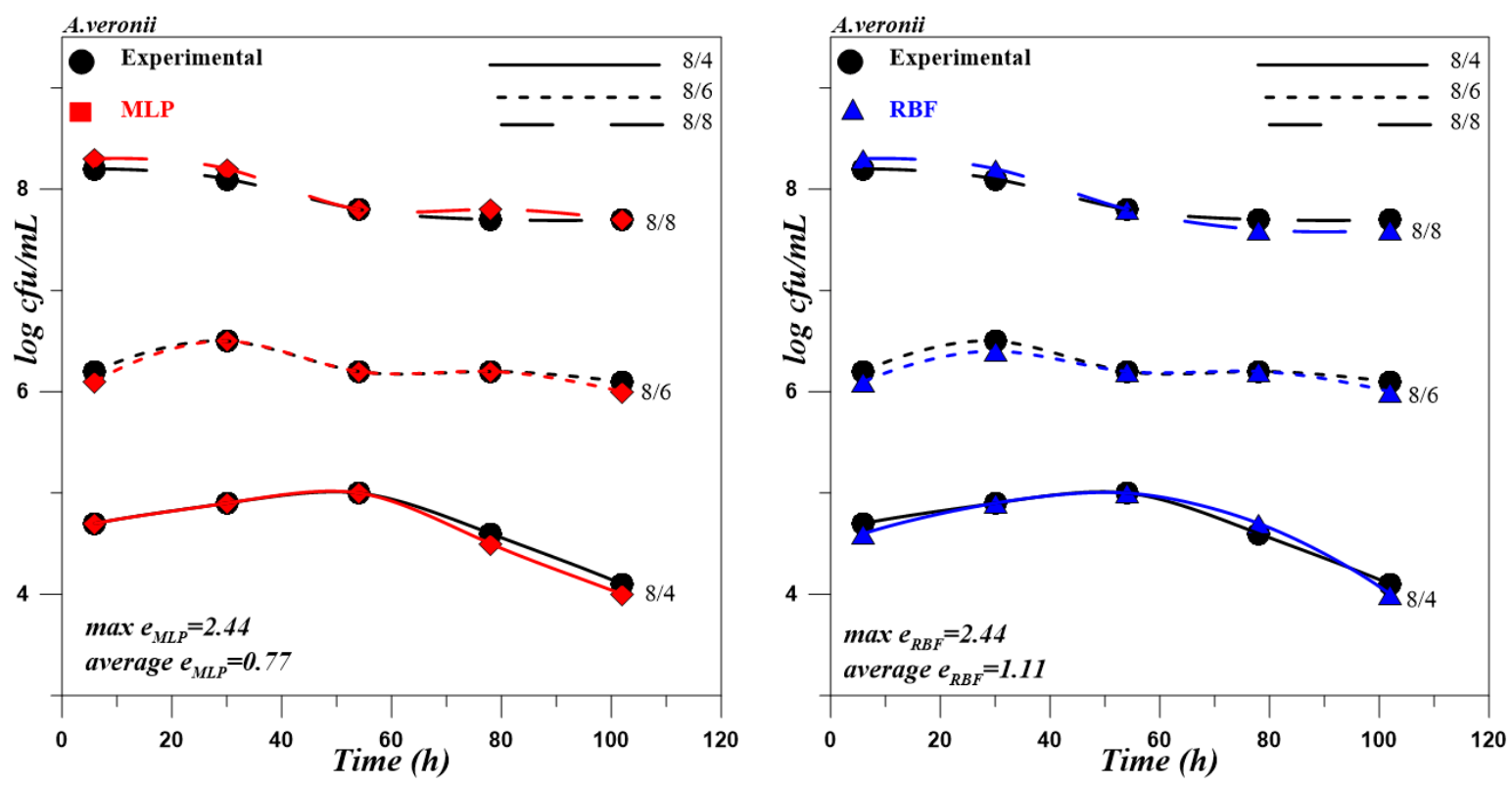

(a)
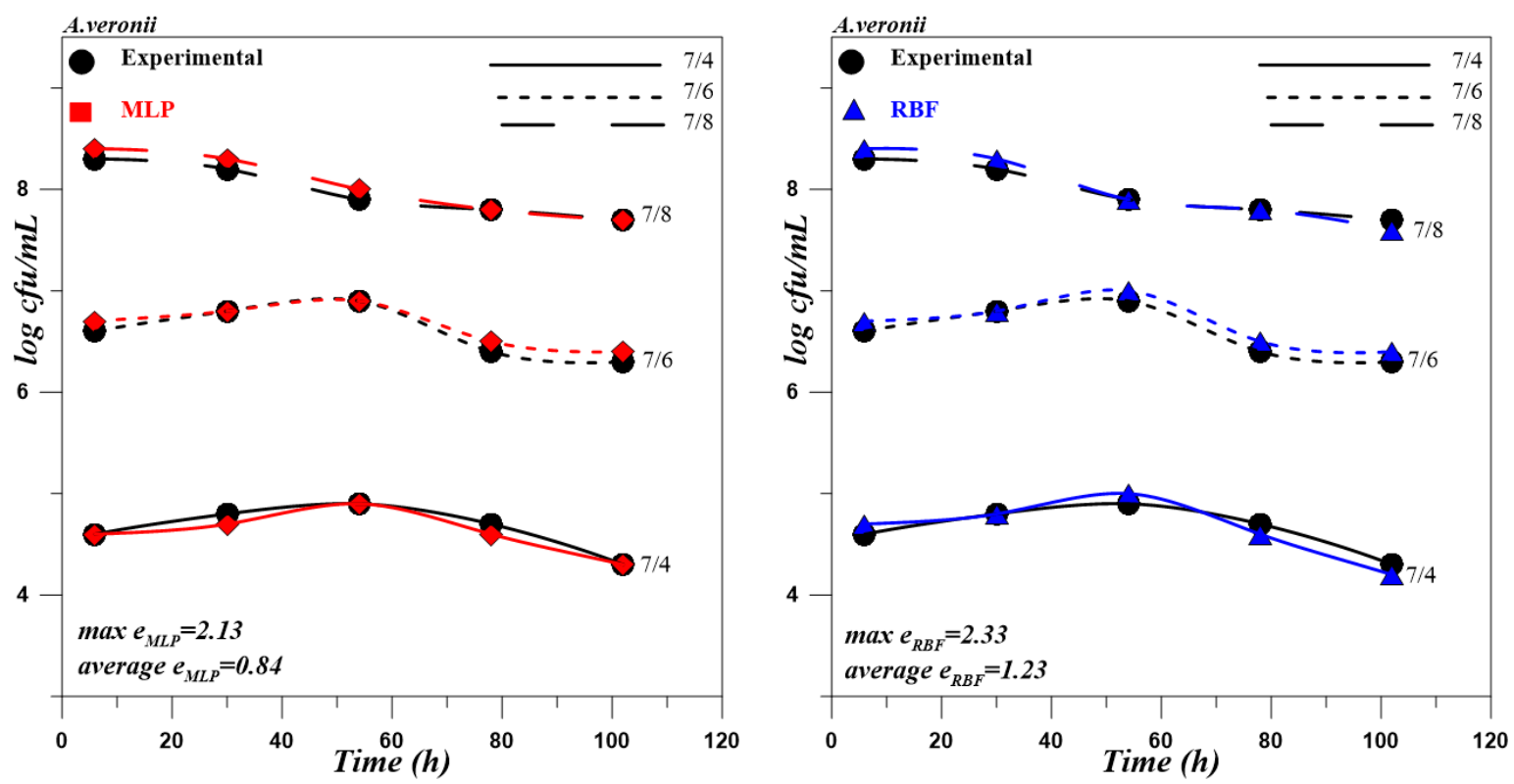

(b) 

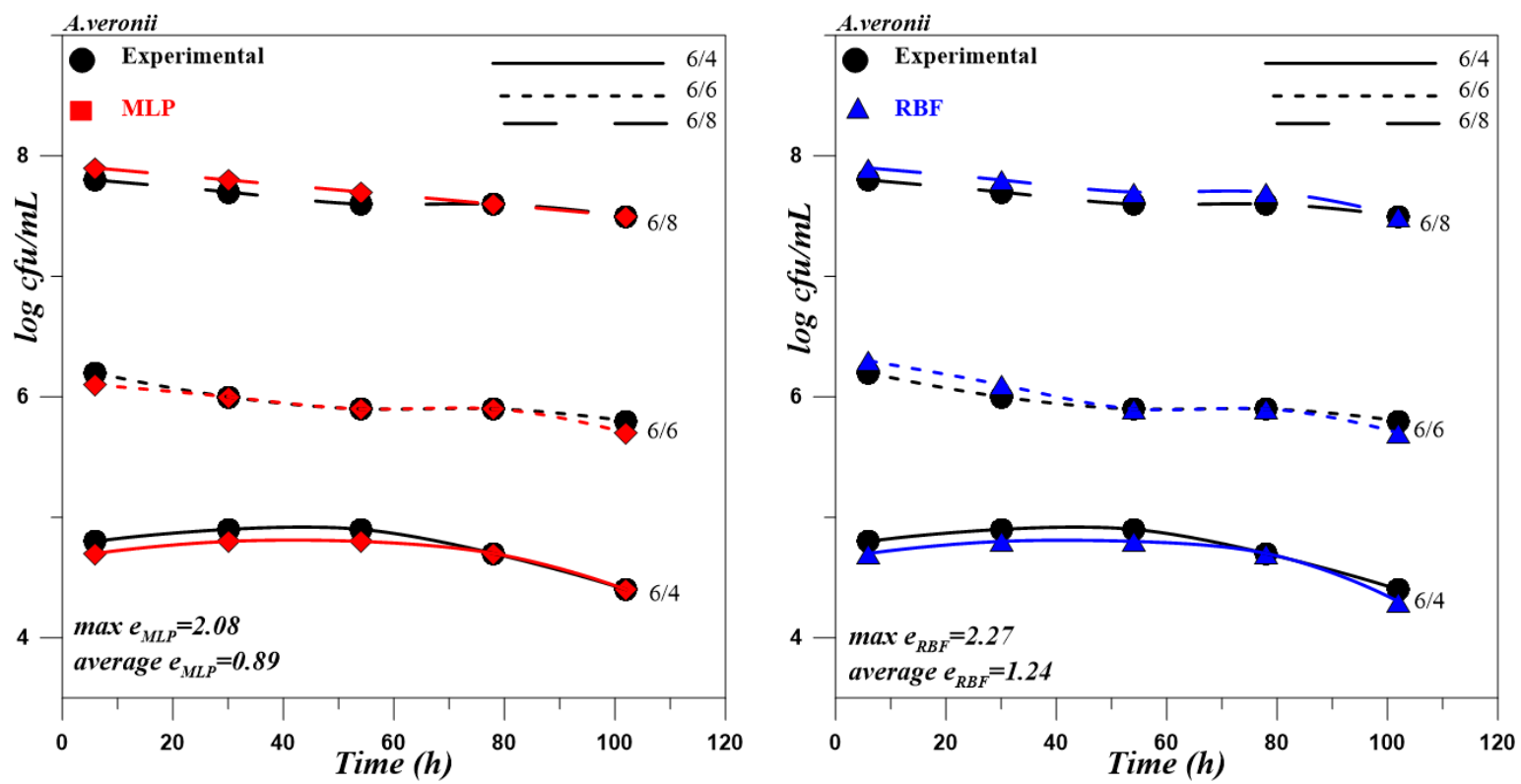

(c)
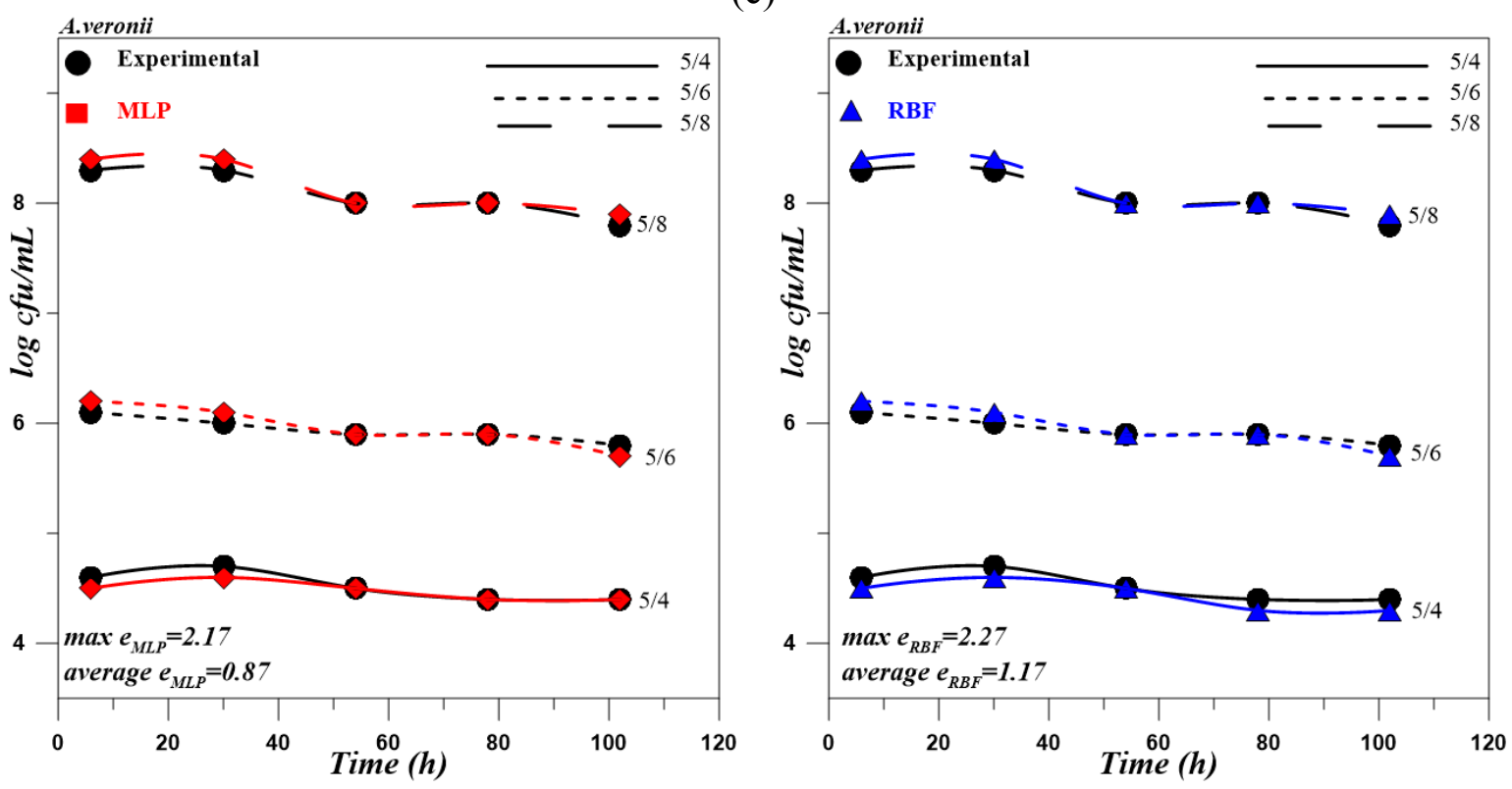

(d) 

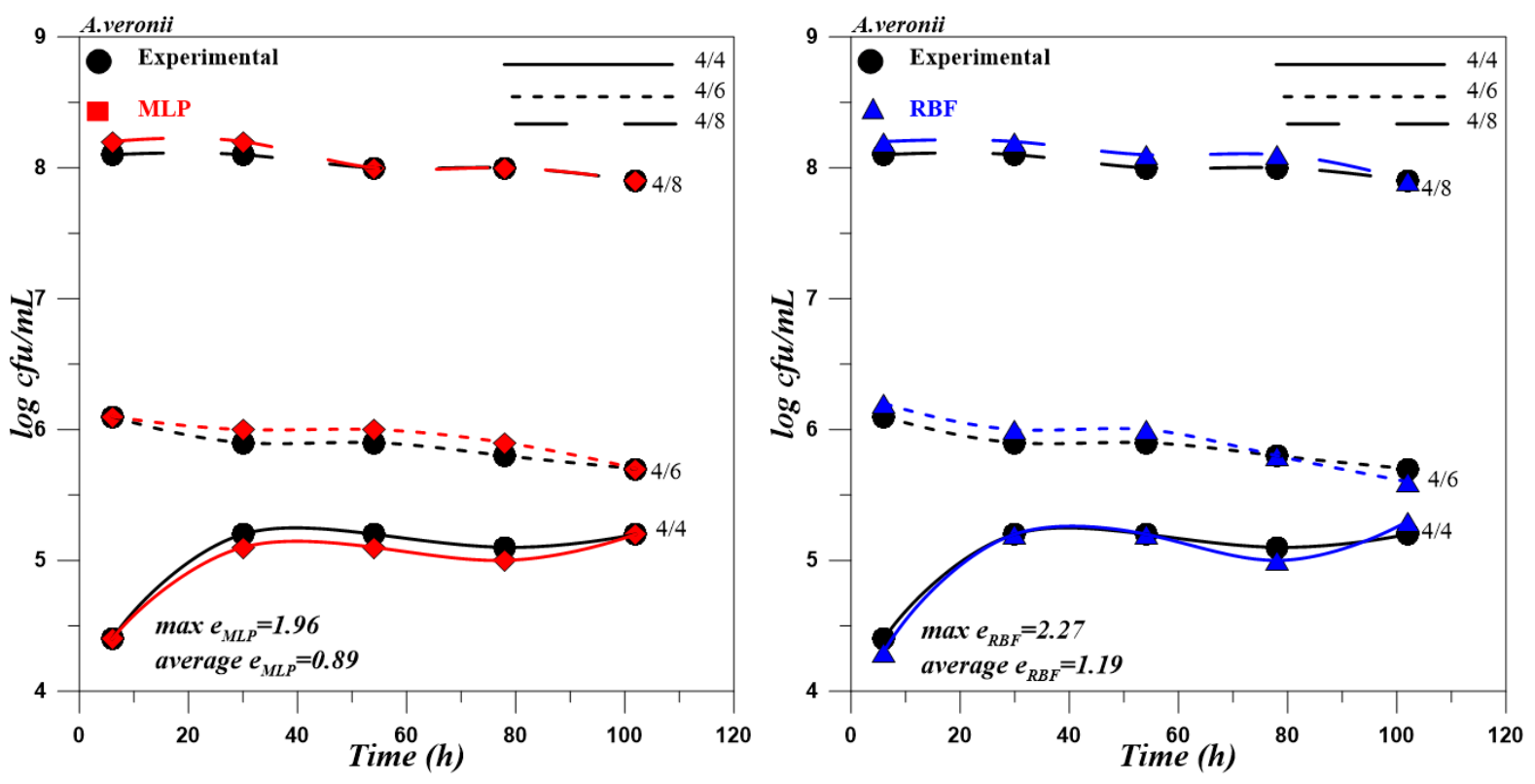

(e)

Fig. 3. The comparison of neural network model predictions and experimental outputs for the concentrations of $A$. veronii co-cultured with $L$. lactis. The initial concentrations of $A$. veronii were $1.0 \times 10^{4} \mathrm{cfu} / \mathrm{mL}, 1.0 \times 10^{6} \mathrm{cfu} / \mathrm{mL}$ and $1.0 \times 10^{8} \mathrm{cfu} / \mathrm{mL}$ and initial concentrations of $L$. lactis were (a) $1.0 \times 10^{8} \mathrm{cfu} / \mathrm{mL}$ (b) $1.0 \times 10^{7} \mathrm{cfu} / \mathrm{mL}$ (c) $1.0 \times 10^{6} \mathrm{cfu} / \mathrm{mL}$ (d) $1.0 \times 10^{5}$ $\mathrm{cfu} / \mathrm{mL}$ (e) $1.0 \times 10^{4} \mathrm{cfu} / \mathrm{mL}$

The RMSE of $A$. hydrophila was calculated as $\mathrm{RMSE}_{\mathrm{MLP}}=0.073937$ and $\mathrm{RMSE}_{\mathrm{RBF}}=0.084853$. The $\mathrm{R}^{2}$ of $A$. hydrophila was calculated as $\mathrm{R}_{\mathrm{MLP}}^{2}=0.996797$ and $\mathrm{R}_{\mathrm{RBF}}^{2}=0.995645$ (Fig. 4).

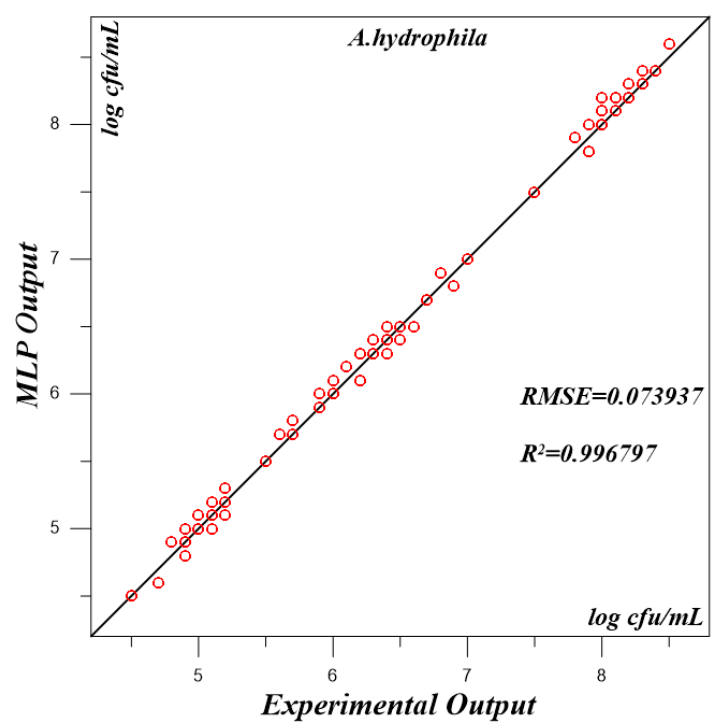

(a)

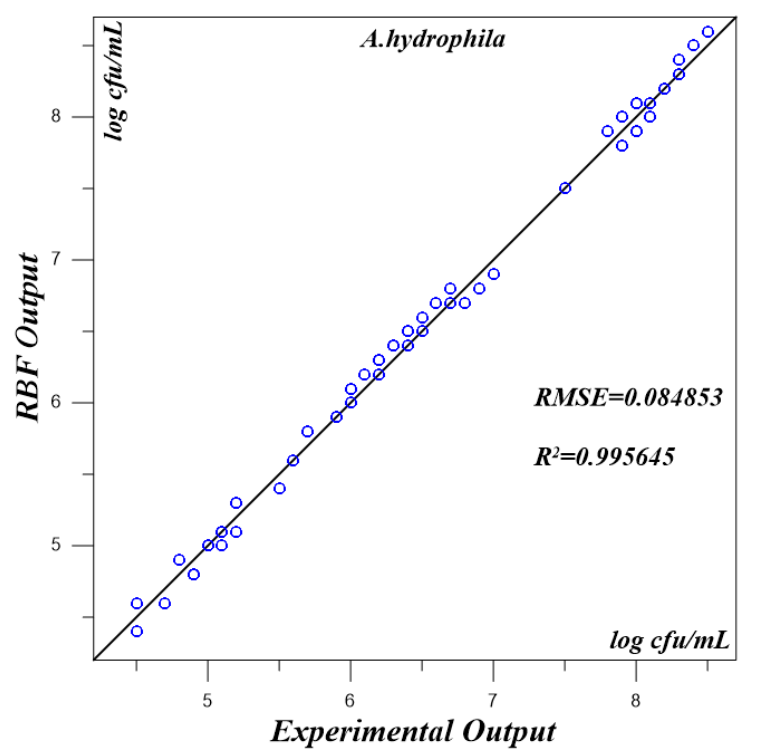

(b)

Fig. 4. Correlation between neural network model predictions and experimental outputs for $A$. hydrophila 
Figure 5 shows the concentrations of $A$. hydrophila co-cultured with L. lactis. As shown in the figure, the average relative errors of $A$. hydrophila were calculated as $e_{M L P}=0.82 \%$ and $e_{R B F}=1.15 \%$.
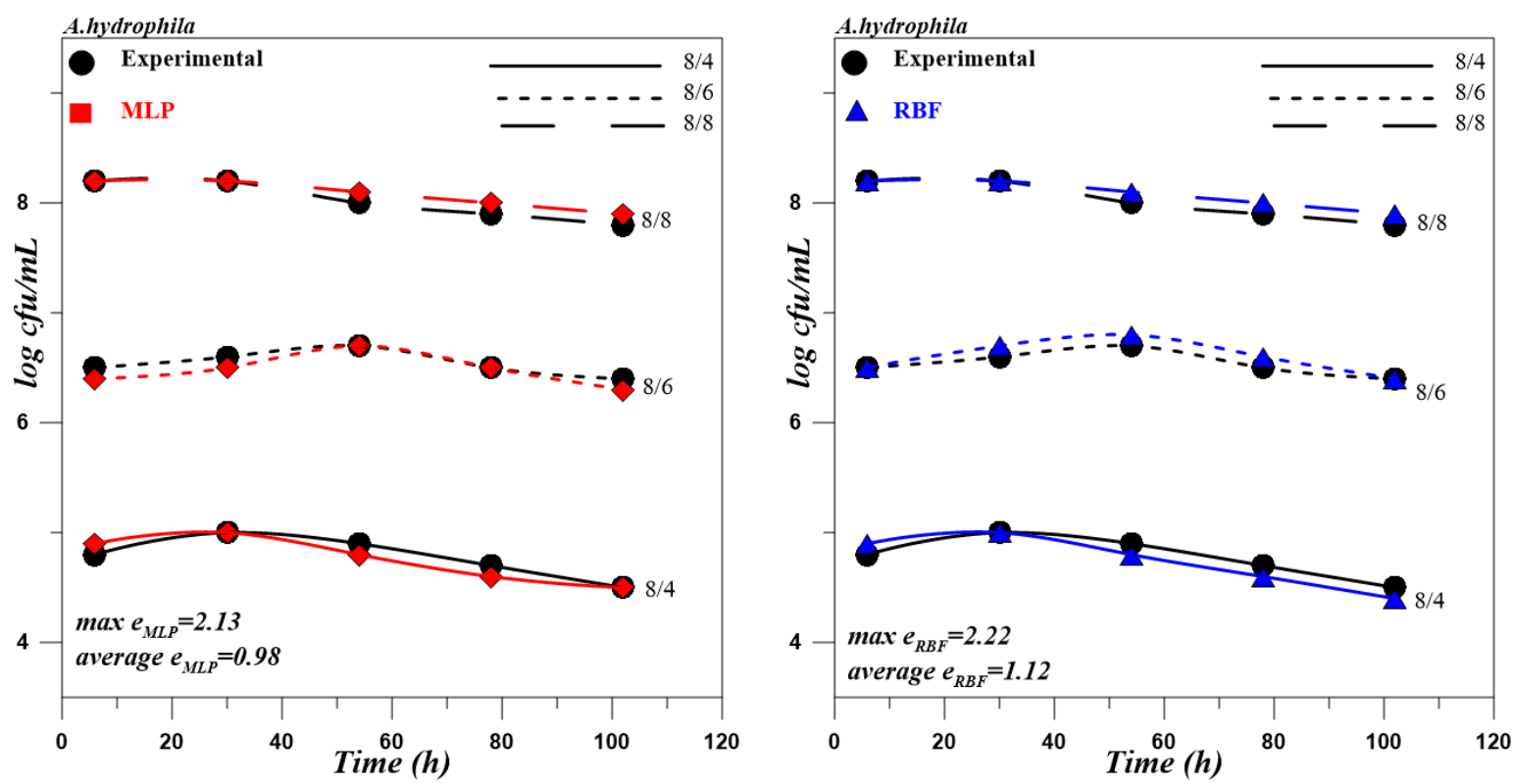

(a)
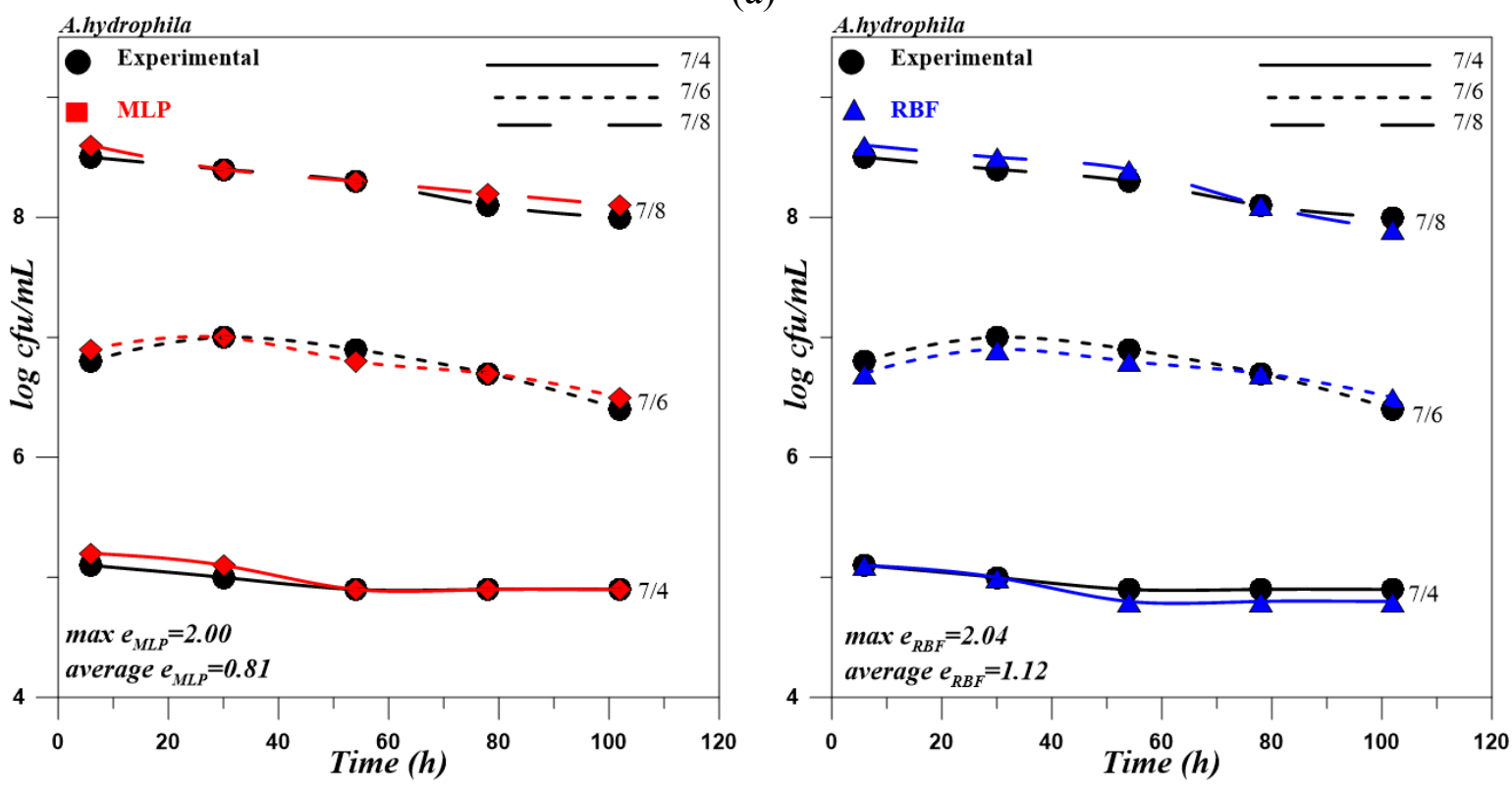

(b) 

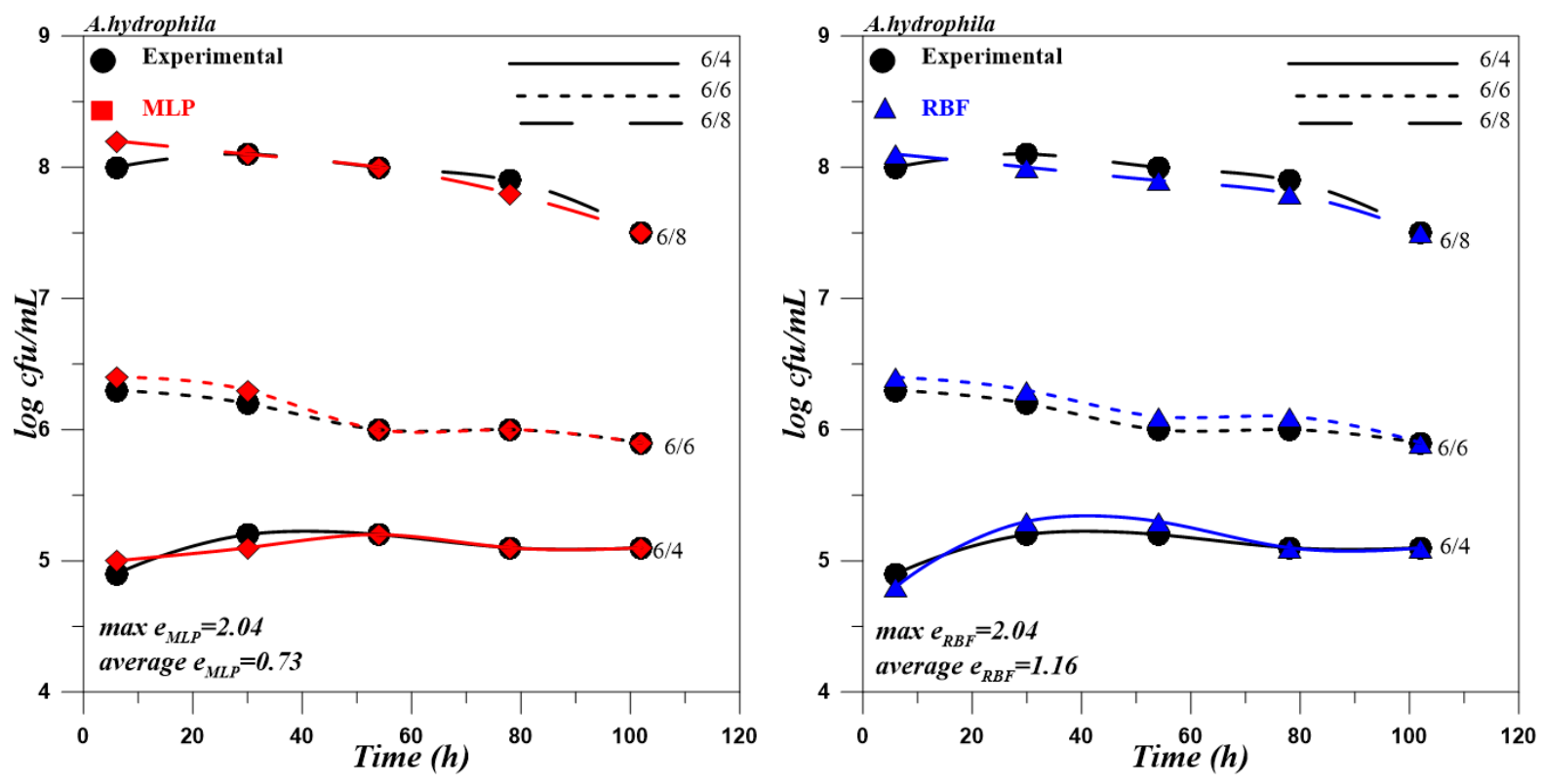

(c)
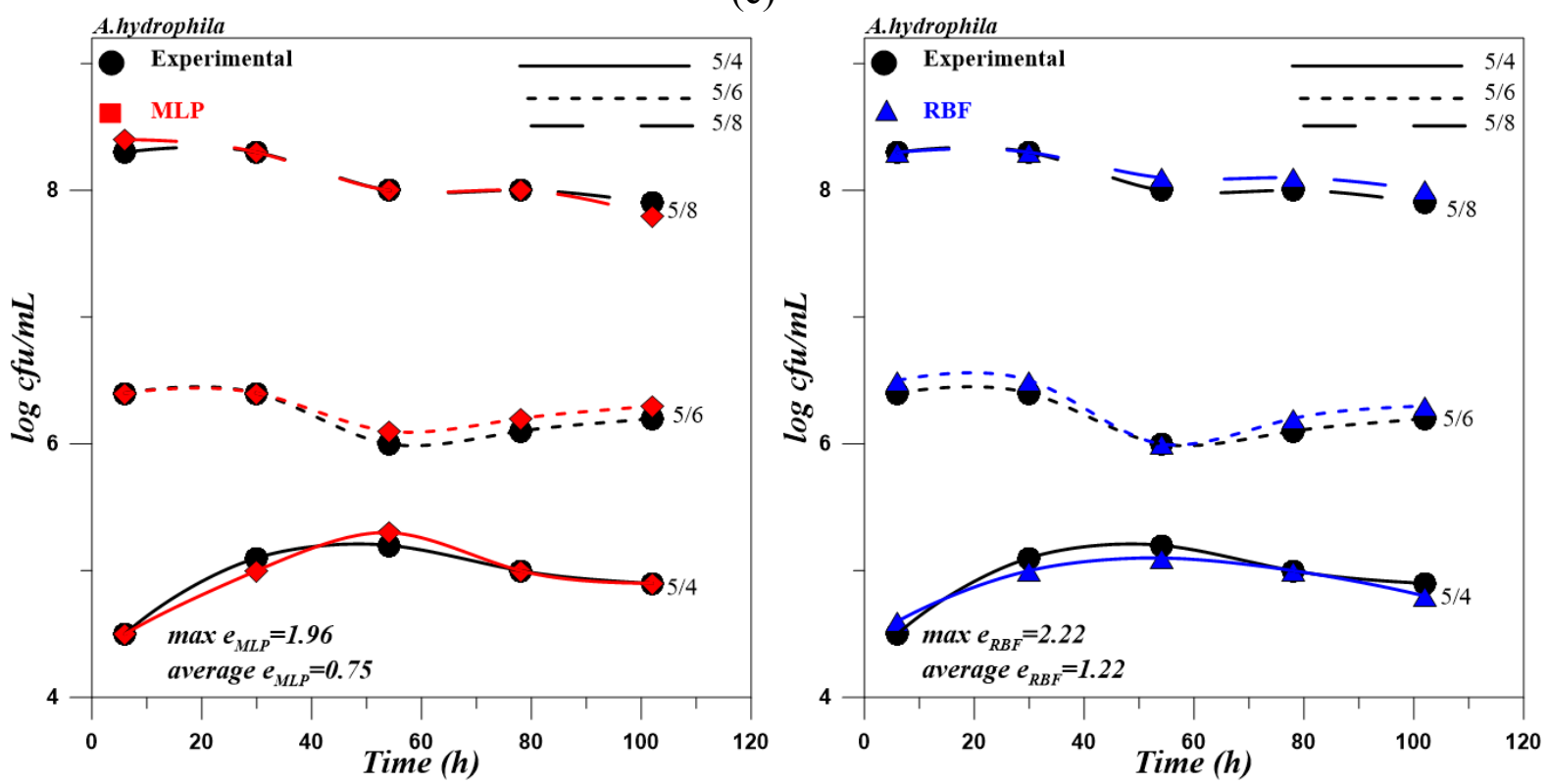

(d) 

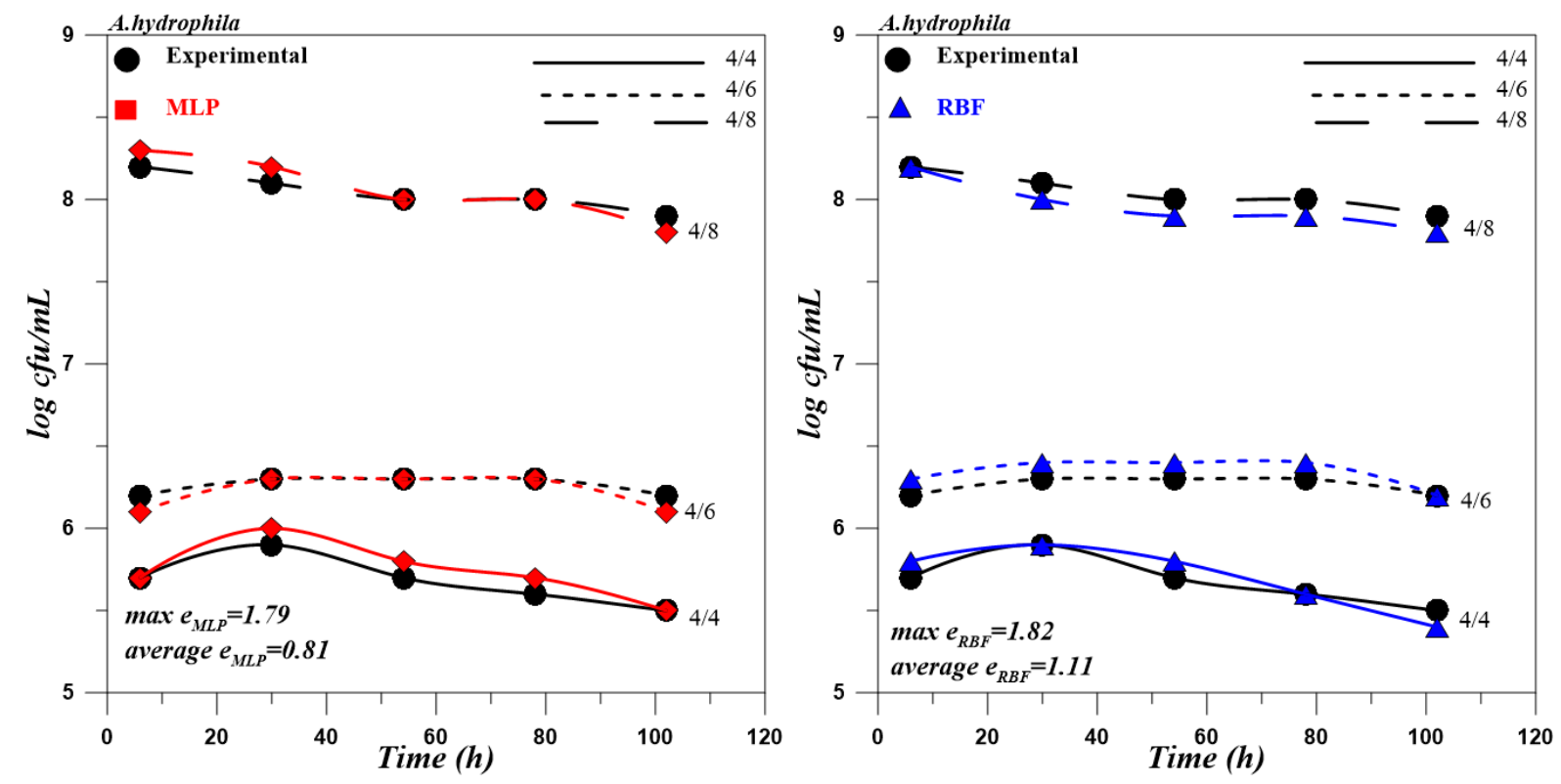

(e)

Fig. 5. The comparison of neural network model predictions and experimental outputs for the concentrations of $A$. hydrophila co-cultured with L. lactis. The initial concentrations of $A$.

hydrophila were $1.0 \times 10^{4} \mathrm{cfu} / \mathrm{mL}, 1.0 \times 10^{6} \mathrm{cfu} / \mathrm{mL}$ and $1.0 \times 10^{8} \mathrm{cfu} / \mathrm{mL}$ and initial concentrations of L. lactis were (a) $1.0 \times 10^{8} \mathrm{cfu} / \mathrm{mL}$ (b) $1.0 \times 10^{7} \mathrm{cfu} / \mathrm{mL}$ (c) $1.0 \times 10^{6} \mathrm{cfu} / \mathrm{mL}$ (d) $1.0 \times 10^{5} \mathrm{cfu} / \mathrm{mL}$ (e) $1.0 \times 10^{4} \mathrm{cfu} / \mathrm{mL}$

The RMSE of $A$. sobria was calculated as $\mathrm{RMSE}_{\mathrm{MLP}}=0.071181$ and $\mathrm{RMSE}_{\mathrm{RBF}}=0.084063$. The $\mathrm{R}^{2}$ of $A$. sobria was calculated as $\mathrm{R}^{2}{ }_{\mathrm{MLP}}=0.996865$ and $\mathrm{R}_{\mathrm{RBF}}^{2}=0.995571$ (Fig. 6).
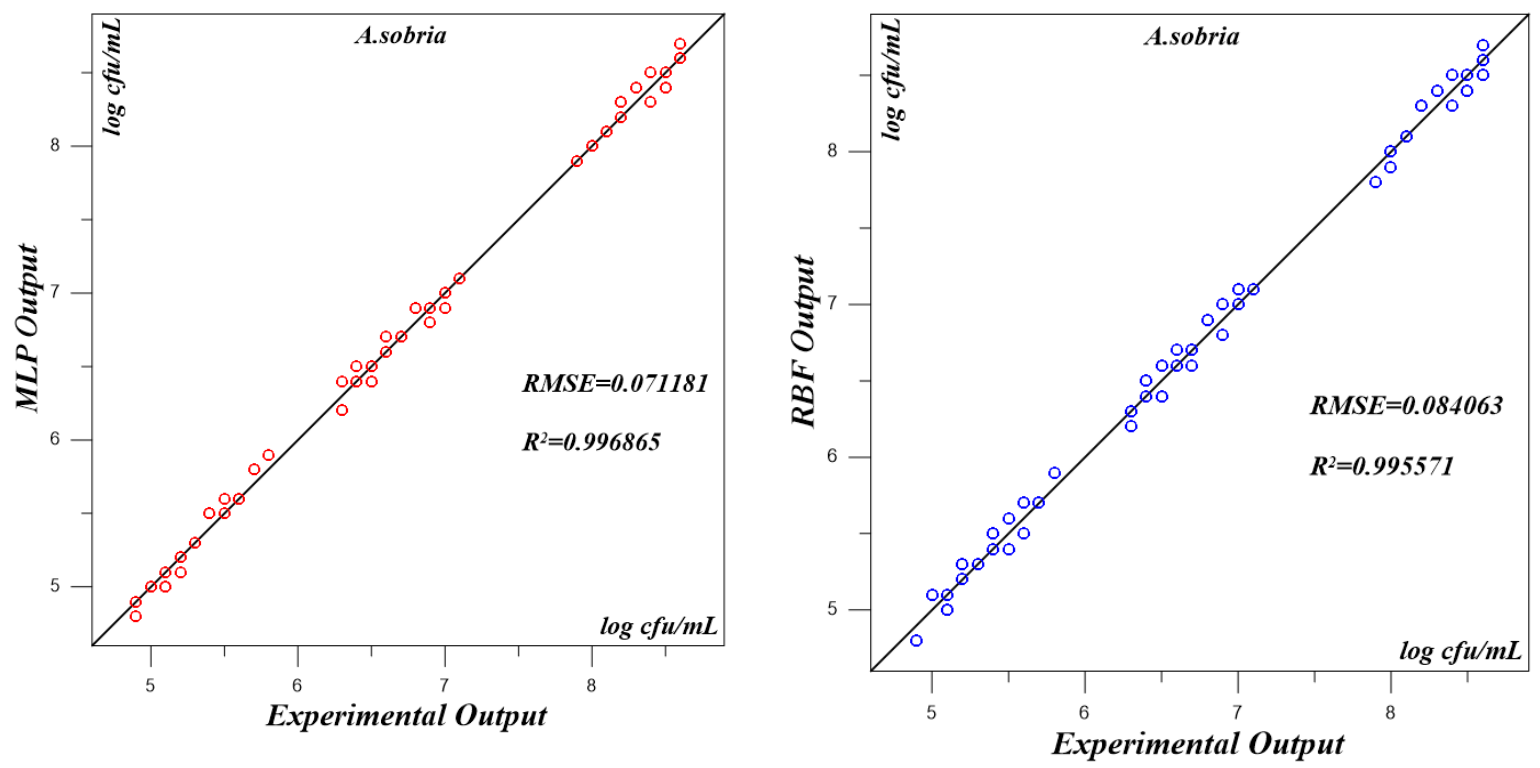

Fig. 6. Correlation between neural network model predictions and experimental outputs for A.sobria

Figure 7 shows the concentrations of $A$. sobria co-cultured with L. lactis. As shown in the figure, the average relative errors of $A$. sobria were calculated as $e_{M L P}=0.79 \%$ and $e_{R B F}=1.10 \%$. 

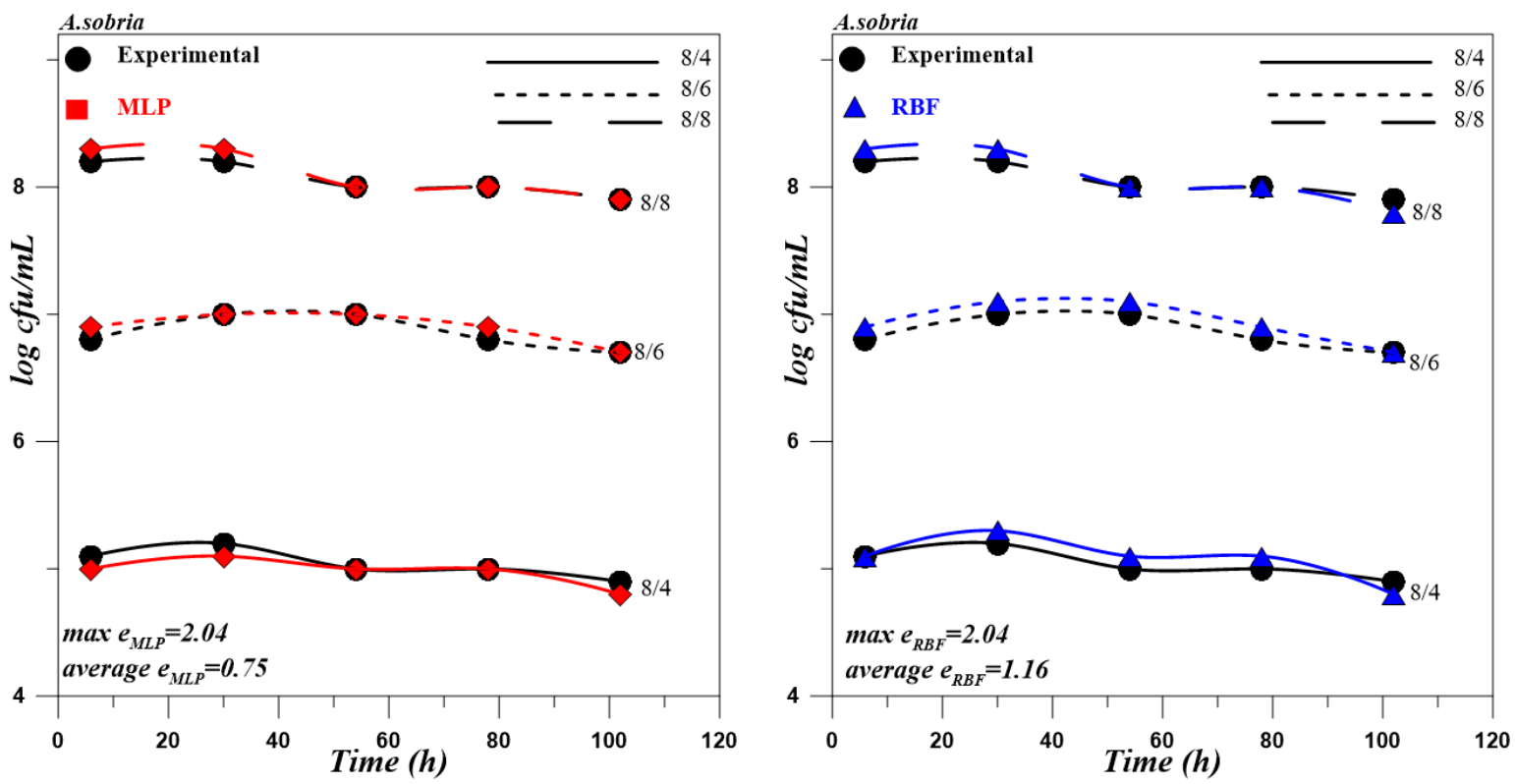

(a)
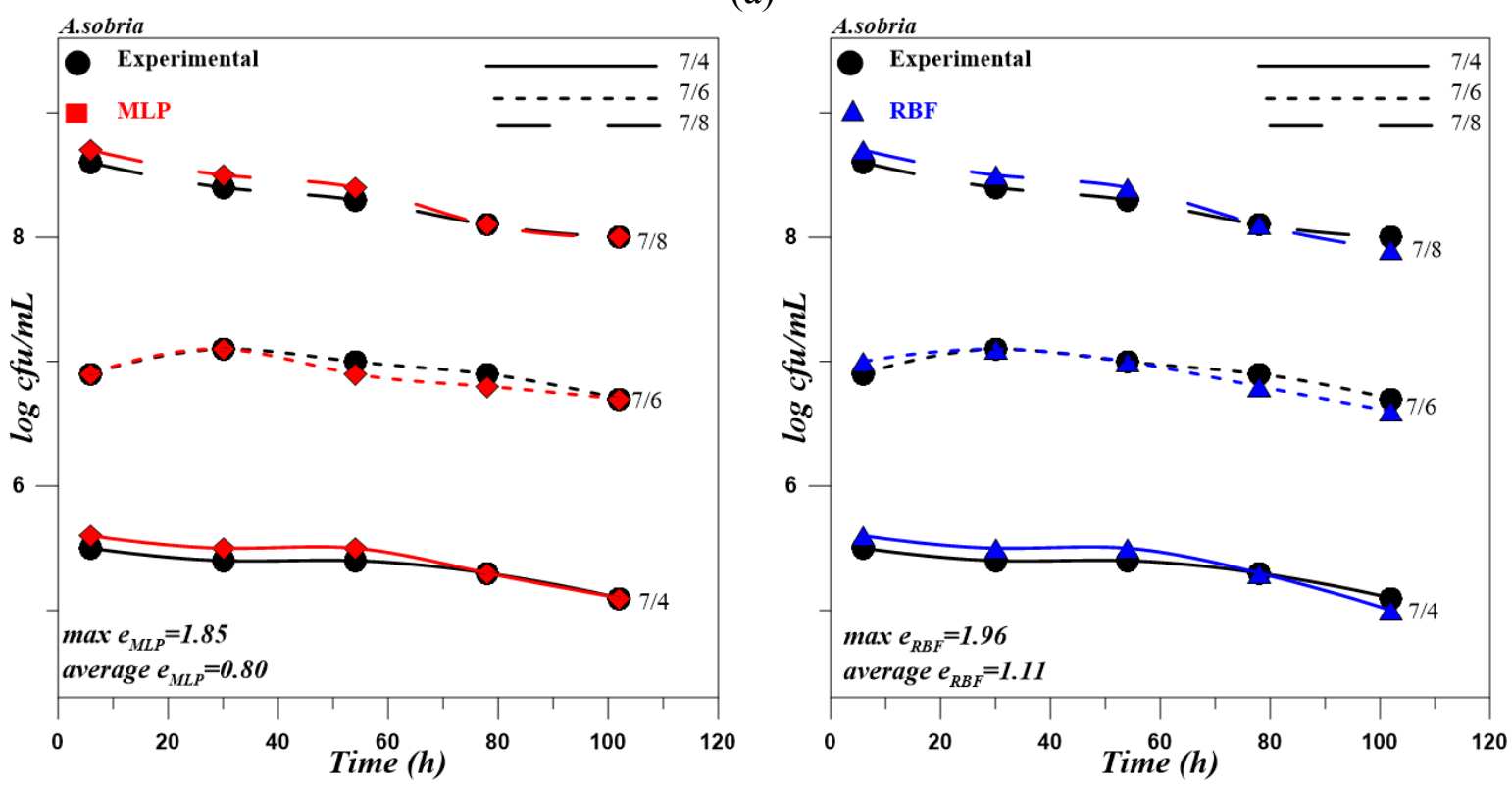

(b) 

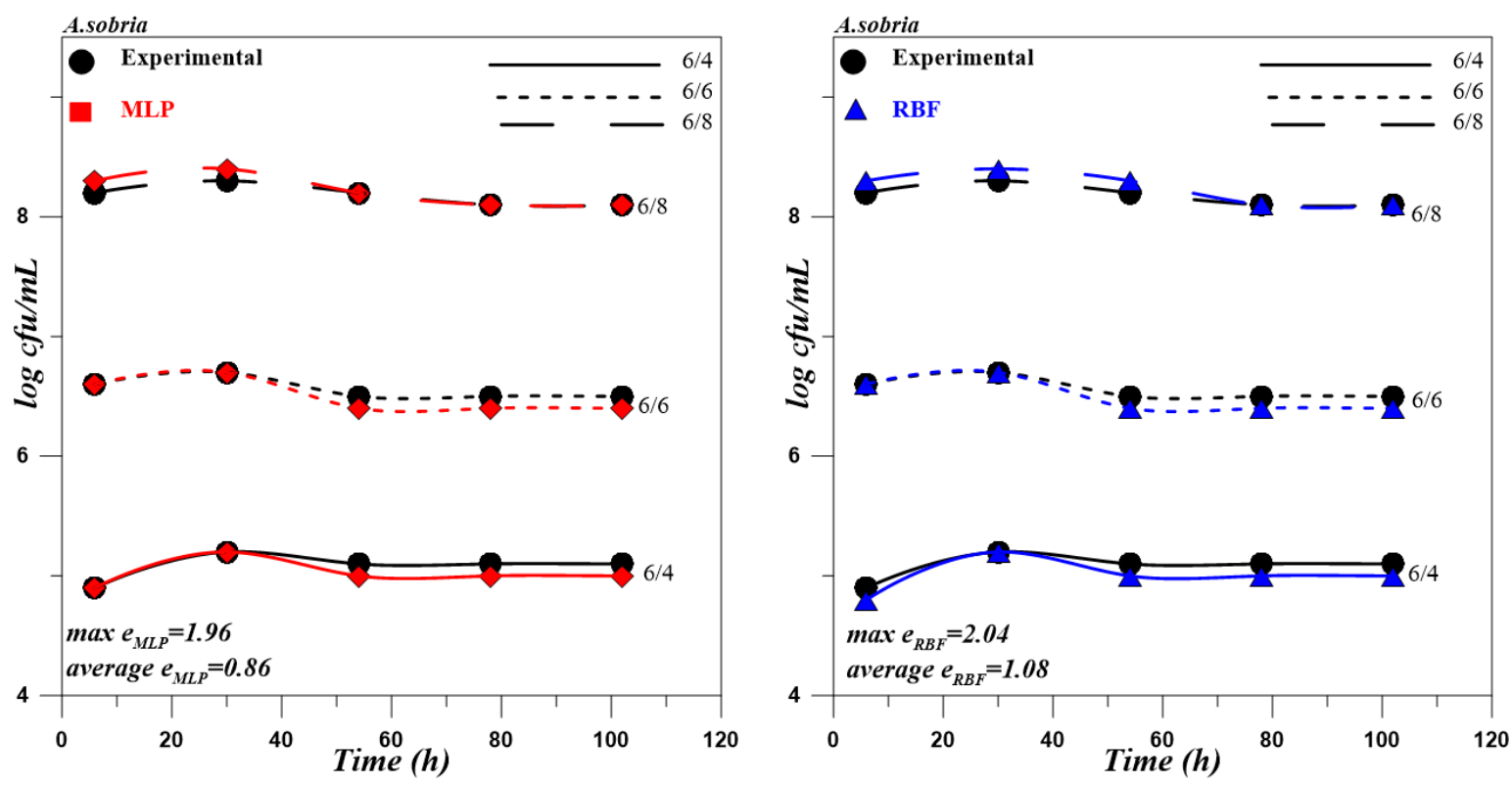

(c)
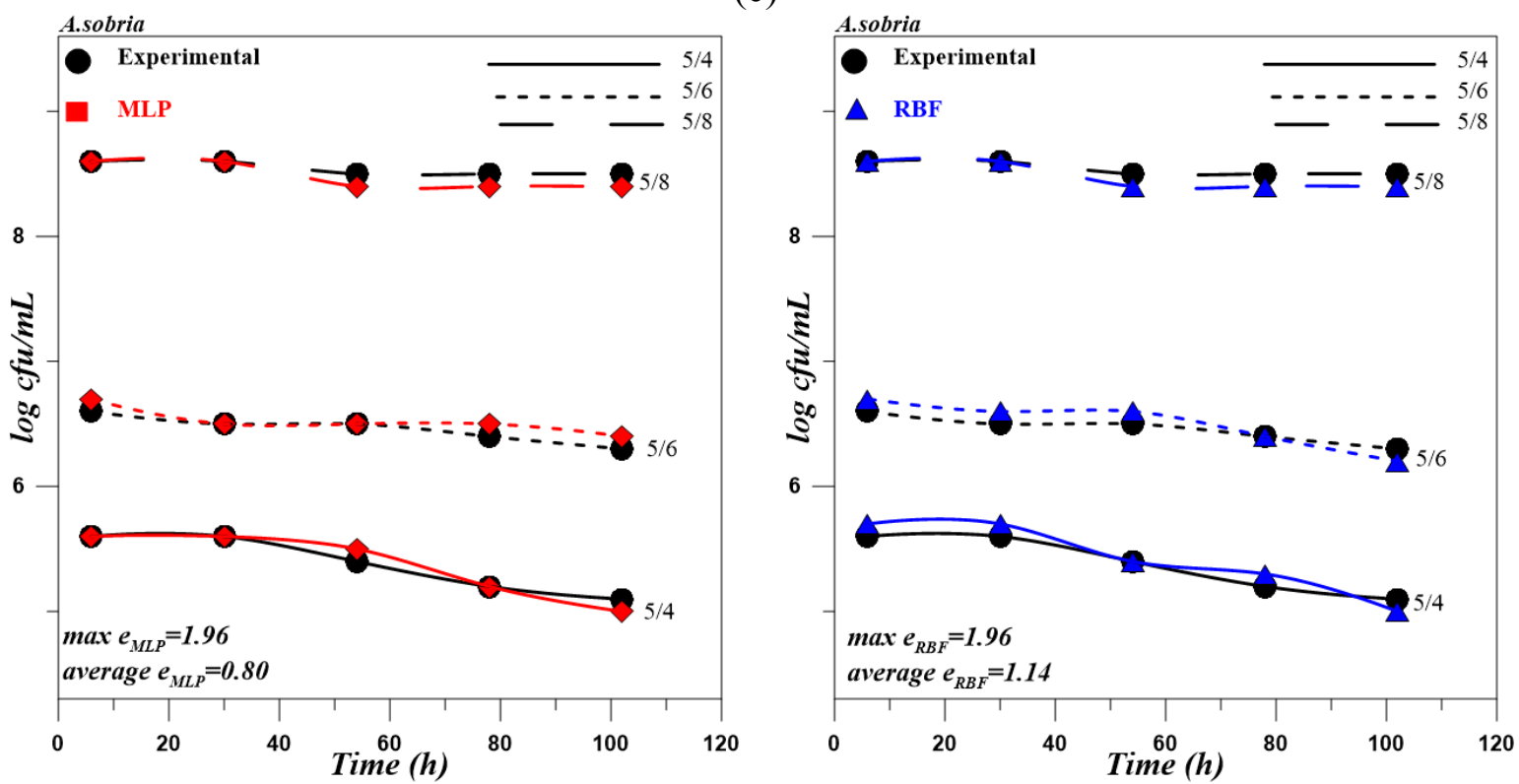

(d) 

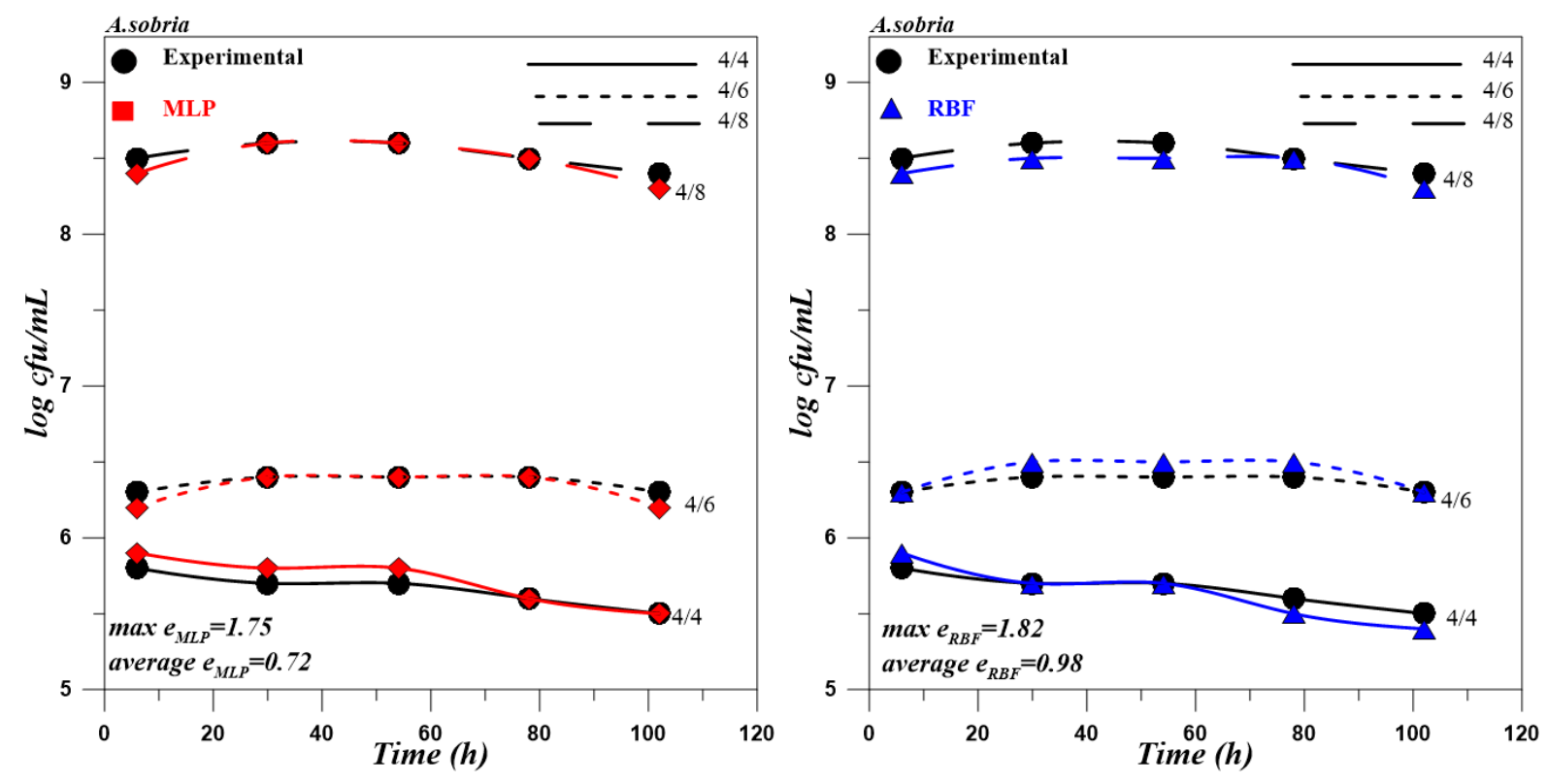

(e)

Fig. 7. The comparison of neural network model predictions and experimental outputs for the concentrations of $A$. sobria co-cultured with $L$. lactis. The initial concentrations of $A$. sobria were $1.0 \times 10^{4} \mathrm{cfu} / \mathrm{mL}, 1.0 \times 10^{6} \mathrm{cfu} / \mathrm{mL}$ and $1.0 \times 10^{8} \mathrm{cfu} / \mathrm{mL}$ and initial concentrations of $L$. lactis were (a) $1.0 \times 10^{8} \mathrm{cfu} / \mathrm{mL}$ (b) $1.0 \times 10^{7} \mathrm{cfu} / \mathrm{mL}$ (c) $1.0 \times 10^{6} \mathrm{cfu} / \mathrm{mL}$ (d) $1.0 \times 10^{5}$ $\mathrm{cfu} / \mathrm{mL}(\mathrm{e}) 1.0 \times 10^{4} \mathrm{cfu} / \mathrm{mL}$

The optimization processes were performed on different parameters of MLP and RBF models to determine the network architecture with the highest accuracy and efficiency in estimating the concentration of Aeromonas spp. in co-culture with L. lactis. The number of neurons in the input and output layers can be determined according to the requirements in the problem, but there is no rule in determining the number of process elements in the hidden layers. A network model with an insufficient or excessive number of neurons in the hidden layer can cause poor generalization and overfitting [49]. The best generalization performance is achieved by trial and error versus network complexity [50]. In the current study, the best MLP and RBF network structures were determined by testing multiple architectures and considering the error rates of the networks. In MLP models the most appropriate network configuration was 3 units for each hidden layer with logistic activation function in hidden and output layer. The number of neurons in the hidden layer was different in the RBF models, but in all models the activation function was gaussian in the hidden layer and identity in the output layer. Both network types, with the error term sum of squares (sos) produced superior networks. The best of the neural networks recognized are shown in Table 2. 
Table 2. Characteristics of artificial networks that recognize output elements

\begin{tabular}{|c|c|c|c|c|c|c|c|c|}
\hline Network & $\begin{array}{c}\text { ANN } \\
\text { network } \\
\text { model }\end{array}$ & $\begin{array}{l}\text { Learning } \\
\text { error }\end{array}$ & $\begin{array}{c}\text { Testing } \\
\text { error }\end{array}$ & $\begin{array}{l}\text { Validation } \\
\text { error }\end{array}$ & $\begin{array}{l}\text { Learning } \\
\text { algorithm }\end{array}$ & $\begin{array}{l}\text { Error } \\
\text { function }\end{array}$ & $\begin{array}{c}\text { Activation } \\
\text { function in } \\
\text { hidden } \\
\text { layer }\end{array}$ & $\begin{array}{c}\text { Activation } \\
\text { function } \\
\text { in output } \\
\text { layer }\end{array}$ \\
\hline \multirow{4}{*}{$\mathrm{N}_{1}$} & MLP 3-14- & 0.96 & 0.73 & 5.44 & BFGS 105 & SOS & Logistic & Logistic \\
\hline & 1 & & & & & & & \\
\hline & RBF 3-28- & 1.26 & 1.26 & 2.11 & RBFT & SOS & Gaussian & Identity \\
\hline & 1 & & & & & & & \\
\hline \multirow{3}{*}{$\mathrm{N}_{2}$} & MLP 3-3-1 & 2.31 & 4.13 & 2.13 & BFGS 0 & SOS & Exponential & Logistic \\
\hline & RBF 3-26- & 1.0 & 6.21 & 2.49 & RBFT & SOS & Gaussian & Identity \\
\hline & 1 & & & & & & & \\
\hline \multirow{3}{*}{$\mathrm{N}_{3}$} & MLP 3-3-1 & 0.85 & 0.76 & 0.88 & BFGS 37 & SOS & Logistic & Logistic \\
\hline & RBF 3-27- & 0.41 & 1.83 & 1.85 & RBFT & SOS & Gaussian & Identity \\
\hline & 1 & & & & & & & \\
\hline
\end{tabular}

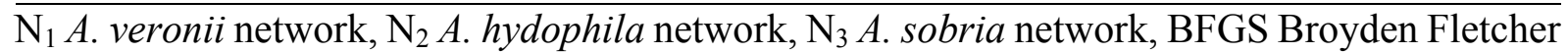
Goldfarb-Shanno, RBFT Reputation-based Byzantine Fault Tolerance, SOS sum of squares

\section{Conclusion}

In this study, two different ANN algorithms, multilayer perceptron (MLP) and radial basis function (RBF) were developed for the prediction of the concentrations of Aeromonas spp. cocultured with L.lactis. The performance and accuracy of proposed MLP and RBF models were tested with the coefficient of determination $\left(\mathrm{R}^{2}\right)$, root mean square error (RMSE) and relative error (e). Both ANN models were showed a strong agreement between the predicted and experimental values. However, the developed MLP models showed higher accuracy and efficiency compared to the RBF models. The results showed that MLP-based models were successful in estimating the concentrations of Aeromonas spp. co-cultured with L. lactis in vitro at different initial concentrations over time. Therefore, this model can be used to determine the bacterial concentrations in the designing of further experiments. Since the network was developed from experimental results under controlled laboratory conditions with environmental parameters kept constant, further research should be conducted to test the applicability of the ANN approach in the variability of these parameters.

\section{References}

[1] Burke, V., Robinson, J., Cooper, M., Beaman, J., Partridge, K., Peterson, D. and Gracey, M., Biotyping and virulence factors in clinical and environmental isolates of Aeromonas species, Applied and Environmental Microbiology, 47, 1146-1149, 1984.

[2] Monfort, P. and Baleux, B., Dynamics of Aeromonas hydrophila, Aeromonas sobria, and Aeromonas caviae in a sewage treatment pond, Applied and Environmental Microbiology, 56, 1999-2006, 1990. 
[3] Janda, J.M. and Abbott, S.L., Evolving concepts regarding the genus Aeromonas: an expanding Panorama of species, disease presentations, and unanswered questions. Clinical Infectious Diseases, 27:332-344.1998.

[4] Teunis, P. and Figueras, M.J., Reassessment of the Enteropathogenicity of mesophilic Aeromonas Species, Frontiers in Microbiology, 7, 1395, 2016.

[5] John, N. and Hatha, A.A.M., Distribution, extracellular virulence factors and drug resistance of motile aeromonads in freshwater ornamental fishes and associated carriage water. International Journal of Fisheries and Aquaculture, 3, 92-100, 2013.

[6] Garcia, F., Pilarski, F., Onaka, E.M, de Moraes, F.R. and Martins, M.L., Hematology of Piaractus mesopotamicus fed diets supplemented with vitamins $\mathrm{C}$ and $\mathrm{E}$, challenged by Aeromonas hydrophila. Aquaculture, 271, 39-46, 2007.

[7] Done, H.Y., Venkatesan, A.K. and Halden, R.U., Does the recent growth of aquaculture create antibiotic resistance threats different from those associated with land animal production in agriculture? The AAPS Journal, 17, 513-524. 2015.

[8] Khemariya, P., Singh, S., Nath, G. and Gulati, A.K., Probiotic Lactococcus lactis: A review. Turkish Journal of Agriculture - Food Science and Technology, 556-652, 2017.

[9] Resende, J.A., Silva, V.L., Fontes, C.O., et al., Multidrug-resistance and toxic metal tolerance of medically important bacteria isolated from an aquaculture system, Microbes and Environments, 27,449-455, 2012

[10] Hossain, S., De Silva B., Dahanayake, P. and Heo, G-J., Characterization of virulence properties and multi-drug resistance profiles in motile Aeromonas spp. isolated from zebrafish (Danio rerio), Letters in Applied Microbiology, 67, 598-605, 2018.

[11] Austin, B., Stuckey, L.E., Robertson, P.A.W., Effendi, I. and Griffith, D.R.W., A probiotic strain of Vibrio alginolyticus effective in reducing disease caused by Aeromonas salmonicida, Vibrio anguillarum and Vibrio ordalli., Journal of Fish Disease, 18, 93-96, 1995.

[12] Moriarty, D.J.W., The role of microorganisms in aquaculture ponds, Aquaculture, 151, 333-349, 1997.

[13] Irianto, A. and Austin, B., Probiotics in aquaculture, Journal of Fish Disease, 25, 633$642,2002$.

[14] Pérez-Sánchez, T., Ruiz-Zarzuela, I., Blas, I. and Balcázar, J.L., Probiotics in aquaculture: a current assessment, Reviews in Aquaculture, 6, 133-146, 2014.

[15] Xia, Y., Lu, M., Chen, G., Cao, J., Gao, F., Wang, M., Liu, Z., Zhang, D., Zhu, H. and Yi, M., Effects of dietary Lactobacillus rhamnosus JCM1136 and Lactococcus lactis subsp. lactis JCM5805 on the growth, intestinal microbiota, morphology, immune response and disease resistance of juvenile Nile tilapia, Oreochromis niloticus, Fish and Shellfish Immunology, 76, 368-379, 2018.

[16]Abumourad, I.M.K., Abbas, W.T., Awaad, E.S., Authman, M.M.N., El-Shafei, K., Sharaf, O.M., Ibrahim, G.A., Sadek, Z.I. and El-Sayed, H.S., Evaluation of Lactobacillus plantarum as a probiotic in aquaculture: emphasis on growth performance and innate immunity, The Journal of Applied Sciences Research, 9, 572-582, 2013. 
[17] Salminen, S., von Wright, A., Morelli, L., Marteau, P., Brassart, D., de Vos, W.M., Fondén, R., Saxelin, M., Collins, K., Mogensen, G., Birkeland, S.E. and Mattila-Sandholm, T., Demonstration of safety of probiotics-a review, International Journal of Food Microbiology, 44, 93-106, 1998

[18] Balcázar, J.L., de Blas, I., Ruiz-Zarzuela, I., Vendrell, D., Gironés, O. and Muzquiz, J.L., Sequencing of variable regions of the 16S rRNA gene for identification of lactic acid bacteria isolated from the intestinal microbiota of healthy salmonids. Comparative Immunology, Microbiology \& Infectious Diseases, 30, 111-118, 2007.

[19] Mauguin, S. and Novel, G., Characterization of lactic acid bacteria isolated from seafood. Applied and Environmental Microbiology Journal, 76, 616-625, 1994.

[20] Sequeiros, C., Vallejo, M., Marguet, E.R. and Olivera, N.L. Inhibitory activity against the fish pathogen Lactococcus garvieae produced by Lactococcus lactis TW34, a lactic acid bacterium isolated from the intestinal tract of a Patagonian fish, Archives of Microbiology, 192, 237-245, 2010.

[21] Nishant, T., Sathish, Kumar, D., Arun Kumar, R., Hima Bindu, K. and Raviteja, Y., Bacteriocin producing probiotic lactic acid bacteria, Journal of Microbial \& Biochemical Technology, 3, 121-124, 2011.

[22] Kumar, M., Jain, A.K., Ghosh, M. and Ganguli, A., Bacteriocin of Lactococcus Lactis. Journal of Food Safety, 32, 369-378, 2012.

[23] Messi, P., Bondi, M., Sabia, C., Battini, R. and Manicardi, G., Detection and preliminary characterization of a bacteriocin (plantaricin 35d) produced by a Lactobacillus plantarum strain, International Journal of Food Microbiology, 64, 193-198, 2001.

[24] Todorov, S. and Dicks, L.M.T., Pediocin ST18, an anti-listerial bacteriocin produced by Pediococcus pentosaceus ST18 isolated from boza, a traditional cereal beverage from Bulgaria, Process Biochemistry, 40, 365-370, 2005.

[25] Ayeni, F. A., Sánchez, B., Adeniyi, B.A., de Los Reyes-Gavilán, C.G., Margolles, A. and Ruas-Madiedo, P., Evaluation of the functional potential of Weissella and Lactobacillus isolates obtained from Nigerian traditional fermented foods and cow's intestine, International Journal of Food Microbiology, 147, 97-104, 2011.

[26] Jacobsen, C.N., Rosenfeldt, Nielsen, V., Hayford, A.E., Møller, P.L., Michaelsen, K.F., Paerregaard, A., Sandström, B., Tvede, M. and Jakobsen, M., Screening of probiotic activities of forty-seven strains of Lactobacillus spp. by in vitro techniques and evaluation of the colonization ability of five selected strains in humans, Applied and Environmental Microbiology, 65, 4949-4956, 1999.

[27] Zielińska, D., Rzepkowska, A., Radawska, A. and Zieliński, K., in vitro screening of selected probiotic properties of Lactobacillus strains isolated from traditional fermented cabbage and cucumber, Current Microbiology, 70, 183-194, 2015.

[28] Begley, M., Gahan, C.G.M. and Hill, C., The interaction between bacteria and bile, FEMS Microbiology Reviews, 29, 625-651, 2005.

[29] Tjørve, K.M.C. and Tjørve, E., The use of Gompertz models in growth analyses, and new Gompertz-model approach: An addition to the Unified-Richards family, PloS One, 12, e0178691, 2017. 
[30] Hiura, S. Koseki, S. and Koyama, K., Prediction of population behavior of Listeria monocytogenes in food using machine learning and a microbial growth and survival database, Scientific Reports, 11, 10613, 2021.

[31] Kim, K. and Hong, J.S.A., Hybrid decision tree algorithm for mixed numeric and categorical data in regression analysis, Pattern Recognition Letters, 98, 39-45, 2017.

[32] Hajmeer, M., Basheer, I. and Cliver, D.O., Survival curves of Listeria monocytogenes in chorizos modeled with artificial neural networks. Food Microbiology , 23, 561-570, 2006.

[33] Uzun Yaylac1, E., Yaylac1, M., Ölmez, H. and Birinci, A., Artificial neural network calculations for a receding contact problem, Computers and Concrete , 25, 551-563, 2020.

[34] Yaylacı, M., Eyüboğlu, A., Adıyaman, G., Uzun Yaylacı, E., Öner, E. and Birinci, A., Assessment of different solution methods for receding contact problems in functionally graded layered mediums, Mechanics of Materials 154, 103730, 2021.

[35] Trujillo, M.C.R., Alarcon, T.E., Dalmau, O.S. and Ojeda, A.Z., Segmentation of carbon nanotube images through an artificial neural network, Soft Computing, 21, 611-625, 2017.

[36] Yan, H., Jiang, Y., Zheng, J., Peng, C. and Li, Q., A multilayer perceptron based medical decision support system for heart disease diagnosis, Expert Systems With Applications, 30, 272-81, 2006.

[37] Uzun Yaylacı E., Developing a differentiation technique for the pathogenic bacteria causing disease in sea bass (Dicentrarchus labrax) by using artificial neural networks. Doctoral thesis, Karadeniz Technical University, The Graduate School of Natural and Applied Sciences, Trabzon, Turkey, 47p., 2019

[38] Jarvis, B., Statistical aspects of the microbiological analysis of foods. Elsevier, Amsterdam, 1989

[39] Panagou, E.Z., Tassou, C.C., Saravanos, E.K. and Nychas, G.J., Application of neural networks to simulate the growth profile of lactic acid bacteria in green olive fermentation. Journal of Food Protection, 70, 1909-1916, 2007.

[40] Fath, A.H., Madanifar, F. and Abbasi, M., Implementation of multilayer perceptron (MLP) and radial basis function $(\mathrm{RBF})$ neural networks to predict solution gas-oil ratio of crude oil systems, Petroleum, 6, 80-91, 2020.

[41] Cakiroglu, E., Comez, I. and Erdol, R., Application of artificial neural network to double receding contact problem with a rigid stamp, Structural Engineering and Mechanics, 21, 205-220, 2005.

[42] Yu, H., Xie, T., Paszczynski, S. and Wilamowski, B., Advantages of Radial Basis Function Networks for Dynamic System Design, IEEE Transactions on Industrial Electronics, 58, 5438-5450, 2011.

[43] Bayram, S., Ocal, M., E., Laptali, Oral, E. and Atis, C.D., Comparison of multi-layer perceptron (MLP) and radial basis function (RBF) for construction cost estimation: the case of Turkey, The Journal of Civil Engineering and Management, 22, 480-490, 2016.

[44] Wawrzyniak, J., Application of artificial neural networks to assess the mycological state of bulk stored rapeseeds, Agriculture, 10, 567, 2020. 
[45] Kumar, A., Kundu, S. and Debnath, M., Effects of the probiotics Lactococcus lacttis (MTCC-440) on Salmonella enteric serovar Typhi in co-culture study, Microbial Pathogenesis, 120, 42-46, 2018.

[46] Vaseeharan, B. and Ramasamy, P., Control of pathogenic Vibrio spp. by Bacillus subtilis BT23, a possible probiotic treatment for black tiger shrimp Penaeus monodon, Letters in Applied Microbiology, 36, 83-87, 2003.

[47] Eren, B. and Eyüpoğlu, V., Modelling of recovery efficiency of Ni(II) ion using artificial neural network, in 6th International Advanced Tech-nologies Symposium (IATS'11), 1618 May 2011, Elazı̆̆ Turkey.

[48] Kayadelen, C., Taşkıran, T., Günaydın, O. and Fener, M., Adaptive neuro-fuzzy modeling for the swelling potential of compacted soils, Environmental Earth Sciences, 59, 109-115, 2009.

[49] Orhan, U., Hekim, M. and Ozer, M., EEG signals classification using the K-means clustering and a multilayer perceptron neural network model, Expert Systems With Applications, 38, 13475-13481, 2011.

[50] Le, Cun, Y., Denker, J.S. and Solla, S.A., Optimal brain damage, Advances in Neural Information Processing Systems, 2, 598-605, 1990. 